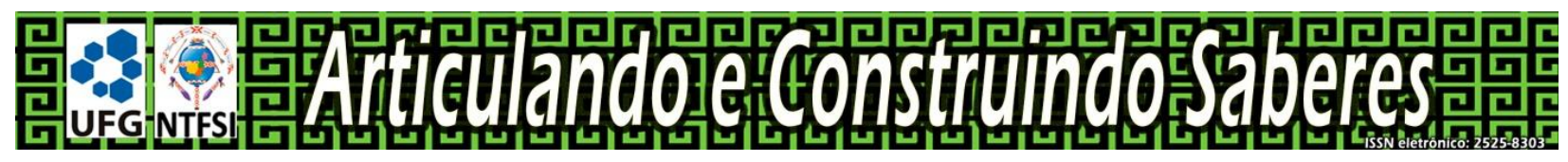

DOI: $10.5216 /$ racs.v6.67313

\title{
Experiência de Estágio como professor de tema contextual
}

\section{Kanari Karaja ${ }^{1}$}

\section{RESUMO}

$\mathrm{O}$ artigo tem como base o conhecimento intracultural e intercultural, transdisciplinar, que se fundamenta através de temas contextuais escolhidos por mim a partir do terceiro ano do Curso de Educação Intercultural de Formação Superior de Professores Indígenas da Universidade Federal de Goiás. Esse curso tem duração de cinco anos, sendo que os dois primeiros anos o aluno estuda na matriz básica e depois entra na matriz específica. Nela, o aluno começa a fazer estágios de I até VI, sendo que o estágio VI é para fazer relatório geral dos estudos e práticas feitas no estágio. Neste relatório, apresento nossos desafios, conquistas e inovações. Durante o período do estágio, adquiri muitos conhecimentos, meus/minhas alunos/as aprenderam a fazer pesquisa, ou seja, aprenderam buscar conhecimentos. Isto é bem semelhante ao modo próprio como as crianças aprendem na nossa comunidade. Nesses cinco anos de estudos, fiz também a pesquisa e a documentação do projeto extraescolar para conclusão do curso. $\mathrm{O}$ projeto extraescolar é feito na minha língua e é parte dos nossos saberes.

PALAVRAS-CHAVE: Estágio. Projeto Extraescolar. Matriz básica. Matriz específica.

\section{Timybo roeryre tyyrtidỹ ỹdumy}

RYBÈ BUTÈ

Kaa tai ijõdirèri bdèèry raruti Iny bdèdỹỹnana, tule tori bdèdỹỹnana, tai tahè tyyrtidu ixidèè ritemyhỹre tidibo raõmysỹdỹỹkremy tyyrti riwahikremy tyyrtina heto-ki, tule tyyrtidu ratyyrtinymyhỹre Educação Intercultural de formação superior de professores Indígenas na UFG kaa tyyrtina iruyrèmy wyra tai tyyrtidu ratyyrtinymyhỹre, urilexè komy inatxi wyramy tyyrtidu ratyyrtinymyhỹre Tyyrti òraruna-ki irahudi tahè tyyrtidu iwitxira-ò ralòmyhỹre tai tahè tyyrtidu Tyyrti wahidỹỹ riòrarunymyhỹre, Tyyrti wahidỹỹ sohoji rbi raòrarumyhỹre tahè aõma-ò raounanamyhỹỹre iruyrè-ò, iounanatyhyxè dèbòò sohojimy reurò-my sõere, tai tahè tyyrtidu timybo raõmysỹdỹỹremy relyymyhỹre ibutumy timybo riwinyre taõmysỹdỹỹna tai sõèmy tyyrtidu ròèrymyhỹre tulesỹ tyyrtidu iruyrèmy wyra aõ riijèmyhỹre idi tatyyrti rahukremy aõma-rki inire Projeto Extraescolar.

RYBÈ WÈRYNA: Estágio. Projeto Extraescolar. Matriz básica. Matriz específica.

${ }^{1}$ Universidade Federal de Goiás (UFG), Goiânia, Goiás, Brasil. E-mail: takinahaky@yahoo.com.br.

R. Articul.const.saber, 2021, v.6: e67313 


\section{Experiencia de pasantía como maestro de tema contextual}

\section{RESUMEN}

El artículo se basa en un conocimiento intracultural e intercultural y transdisciplinario que se fundamenta en temas contextuales elegidos por mí del tercer año del curso de Educación Intercultural para la educación superior de profesores indígenas de la UFG. Este curso tiene una duración de cinco años, los dos años que el estudiante estudia en la matriz básica y luego el estudiante ingresa a la matriz específica en ella el estudiante comienza a hacer las etapas de la I a la V, y la etapa VI es para hacer el informe general de prácticas. . En este informe presentamos nuestros desafíos, logros e innovaciones. Durante el período para adquirir mucho conocimiento, mis alumnos aprendieron a investigar, es decir, aprendieron a buscar conocimientos. Esto es muy similar a la forma en que los niños han aprendido en nuestra comunidad. En estos cinco años de estudios hice investigación y documentación del proyecto extraescolar para completar el curso. El proyecto extraescolar se realiza en mi idioma y es parte de nuestro conocimiento.

PALABRAS ClaVE: Pasantía. Proyecto Fuera de la Escuela. Matriz Básica. Matriz Específica.

\section{Introdução}

Neste texto eu vou contar sobre a minha experiência do estágio pedagógico que eu fiz durante o meu curso de formação docente na Educação Intercultural. Foram cinco anos de estudo, os dois anos primeiros estudei na matriz básica e depois eu entrei na matriz específica na qual eu escolhi me habilitar na área de ciências da linguagem, onde tive a oportunidade de estudar e conhecer ainda mais sobre a minha língua Iny Rybè.

Como qualquer ser humano, tive dificuldade de entender como se dava o estágio na sala, mas com ajuda do meu comitê, de minha orientadora e de meus colegas eu fui aprendendo cada vez mais durante a orientação que acontecia todas as manhãs de sábados, durante a etapa presencial do curso no Núcleo Takinahakỹ e, também, durante a etapa em terra indígena que acontece nas aldeias. Para mim foi uma honra ingressar nesse curso onde criei vários(as) amigos e amigas, conheci novas culturas, costumes, crenças, línguas, cantos, danças etc. Esse curso abriu minha visão em relação a tudo, em relação a minha cultura, língua, crença, canto, dança. Não devemos deixar de praticar aquilo que está presente no conviver do meu povo Iny, antes eu pensava de maneira bem diferente, pensava que a minha cultura e língua estavam fortes, mas quando ingressei nesse curso fui acordando e abrindo a minha mente e graças a esse curso hoje 
percebo que não devo cruzar os meus braços, ver a minha cultura e língua serem extintos. Hoje luto pelo bem de minha cultura e língua.

Atualmente sou professor na Escola Estadual Indígena Krumare, onde trabalho e ensino as crianças e jovens a língua Iny Rybè. Incentivo e converso com meus alunos e alunas para não deixarem de praticar aquilo que está presente na nossa comunidade. Converso sobre como fortalecer ainda mais a cultura e a língua Iny Rybè. Quando comecei a trabalhar na sala de aula, antes eu não tinha muita experiência para trabalhar com alunos, não sabia como planejar a aula. Não tenho vergonha de dizer isso porque ninguém nasce sabendo. Com o passar do tempo eu fui aprendendo no Estágio pedagógico. No estágio, fui aprendendo muita coisa nova, o jeito de trabalhar na sala de aula, saber a diferença entre disciplina e tema contextual. Isso para mim foi essencial na minha experiência como professor de tema contextual.

\section{Referencial epistêmico}

Com as informações contidas nas bases de conhecimentos intercultural e intracultural, fiz a junção desses dois conhecimentos para poder trabalhar no estágio pedagógico do curso. Vou mostrar como trabalhei no Estágio I até Estágio V. O primeiro Estágio que trabalhei foi com o tema contextual "Mudanças Climáticas", que é um tema que abrange conhecimento não Indígena e conhecimento Indígena. $\mathrm{Na}$ verdade, essas mudanças são observadas no mundo não Indígena, também ocorre no mundo Indígena. Essas mudanças afetam a todos que vive nesse mundo. Para compreender como trabalhar com temas contextuais, além das orientações trocadas com minha orientadora e com os colegas de comitê, fiz algumas leituras, para compreender o que é tema contextual e educação intercultural. Segundo Pimentel da Silva (2012; 2016), se os conhecimentos dos temas contextuais são de pertencimentos das tradições indígenas, a língua da composição do tema é a indígena. Já o intercultural, contextualiza-se em outra relação linguística, que ela chama de bilinguismo epistêmico. Concordo com a autora quando ela afirma que muitos conhecimentos Karajá não tem como serem traduzidos. Pereira (2016), reportando a fala oral (José Laurício Tseretó), me faz entender que o tema contextual tem a capacidade de "ajuntar o conhecimento", remetendo a ideia de tema contextual. Além disso, durante esse Estágio fiz pesquisa na internet para obter mais informações sobre meus temas 
contextuais trabalhados no estágio pedagógico. Comecei pesquisando sobre mudanças climáticas, tema do estágio I. Fiz pesquisa na aldeia. Fiz perguntas para uma anciã para obter informações como era antigamente e em relação às mudanças climáticas nas aldeias que ela vivenciou e observou e como estão essas mudanças atualmente. Os dois conhecimentos contribuíram muito para dar início ao estágio I, porque não foi fácil, no início, mas com muita dedicação eu fui aprendendo cada vez mais.

\section{Estágio I: Tema Contextual Mudanças Climáticas}

Do dia 12 ao dia 16 de junho de 2018, comecei a dar aula de Estágio I com o tema contextual "Mudanças Climáticas", na Escola Estadual Indígena Krumare que se localiza na Aldeia JK, na Ilha do Bananal, no Município de Lagoa da Confusão-TO.

No começo do Estágio I, eu tive muita dificuldade de aplicar o estágio dentro da sala de aula, porque eu era uma pessoa muito tímida, por isso tive dificuldade de fazer plano de aula, pesquisa e entrevista. Tudo isso foi para mim um grande desafio na minha formação acadêmica. E depois eu fui aprendendo com minha orientadora e com os colegas do comitê, passo a passo, a fazer pesquisa, entrevista, e plano de aula. Todos os sábados, durante a etapa do curso na UFG, temos reunião de orientação. Nessas reuniões, discutimos o estágio, os princípios pedagógicos da intraculturalidade, interculturalidade e da transdisciplinaridade. Muitas vezes elaboramos coletivamente modelos de plano de aula. Também fazemos um plano de estudo que envolve leituras de textos teóricos, e passos da pesquisa, como por exemplo, anotar os nomes das pessoas com quem pesquisamos.

O primeiro passo que eu fiz foi fazer a pesquisa sobre as mudanças climáticas em site de pesquisa, no qual adquiri um pouco do conhecimento ocidental sobre o tema. Nele, aprendi que a mudança climática é um grande desafio do nosso tempo. Os impactos afetam desde a produção de alimentos até o aumento do nível do mar - aumentando o risco de inundações catastróficas têm desestabilizado as sociedades e o meio ambiente de uma maneira global e sem precedente. Também entrevistei uma anciã Mahãlaru Karajá, da aldeia vizinha, de nome Santa Isabel do Morro -TO, além dela ser anciã, ela também é minha avó paterna.

R. Articul.const.saber, 2021, v.6: e67313 
Com essas pesquisas eu fui aprofundando o meu conhecimento sobre as mudanças climáticas e comecei a fazer o plano de aula para por em prática no estágio, na sala de aula. No primeiro Estágio, trabalhei com a turma da EJA. Comecei no dia 12 de junho de 2017 e terminei a aula no dia 16. A aula com esse tema contextual durou de 5 dias.

No primeiro dia de aula eu fiz uma pergunta para os alunos: o que é um tema contextual? Mas ninguém soube me responder e depois eu tive que explicar sobre o tema contextual: $\mathrm{O}$ tema contextual é uma aula que aborda vários conhecimentos dentro de um só tema. Envolve conhecimento ocidental e conhecimento intracultural que vai se esticando e aumentando o nosso entendimento sobre o que estamos estudando. Para entrar no contexto do tema, eu fiz uma outra pergunta "Na visão de vocês, quais foram as mudanças climáticas que vocês observaram ou sentiram ao longo desses anos que se passaram"? Os alunos responderam dizendo que as mudanças que observaram e sentiram foi o aumento da temperatura do clima; período de chuva fora de época, pois chove no mês de outubro quando não é o tempo certo para chover; o nível do rio fica baixo no período de cheia do rio Araguaia, o nível do rio Araguaia fica mais baixo no período de seca, redução de cardumes no período de cheia do rio Araguaia, e muitas queimadas dentro da Ilha do Bananal.

Figura 1 - Turma da EJA fazendo desenhos sobre as mudanças climáticas

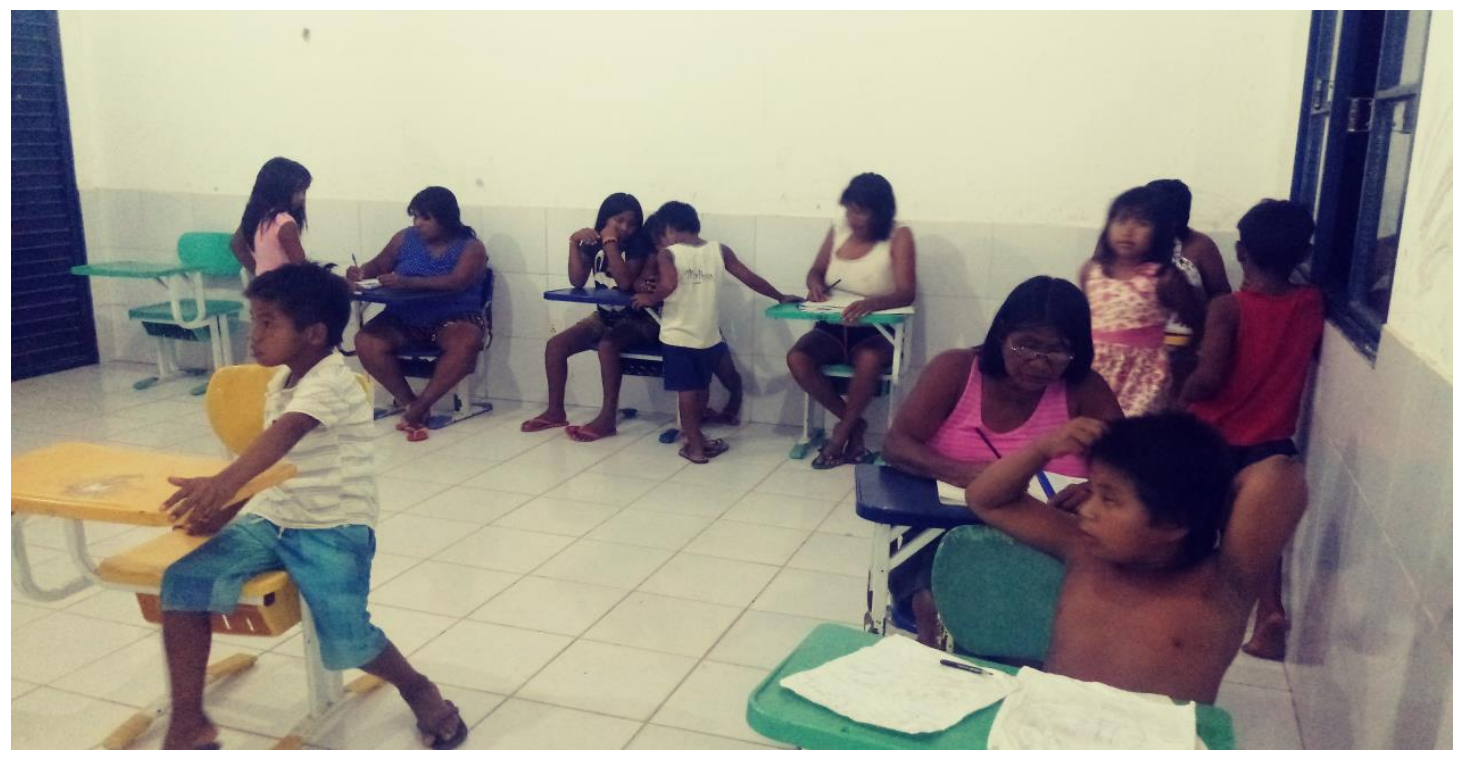

Fonte: Kanari Karajá (2018). 
Figura 2 - Desenhos sobre as mudanças climáticas

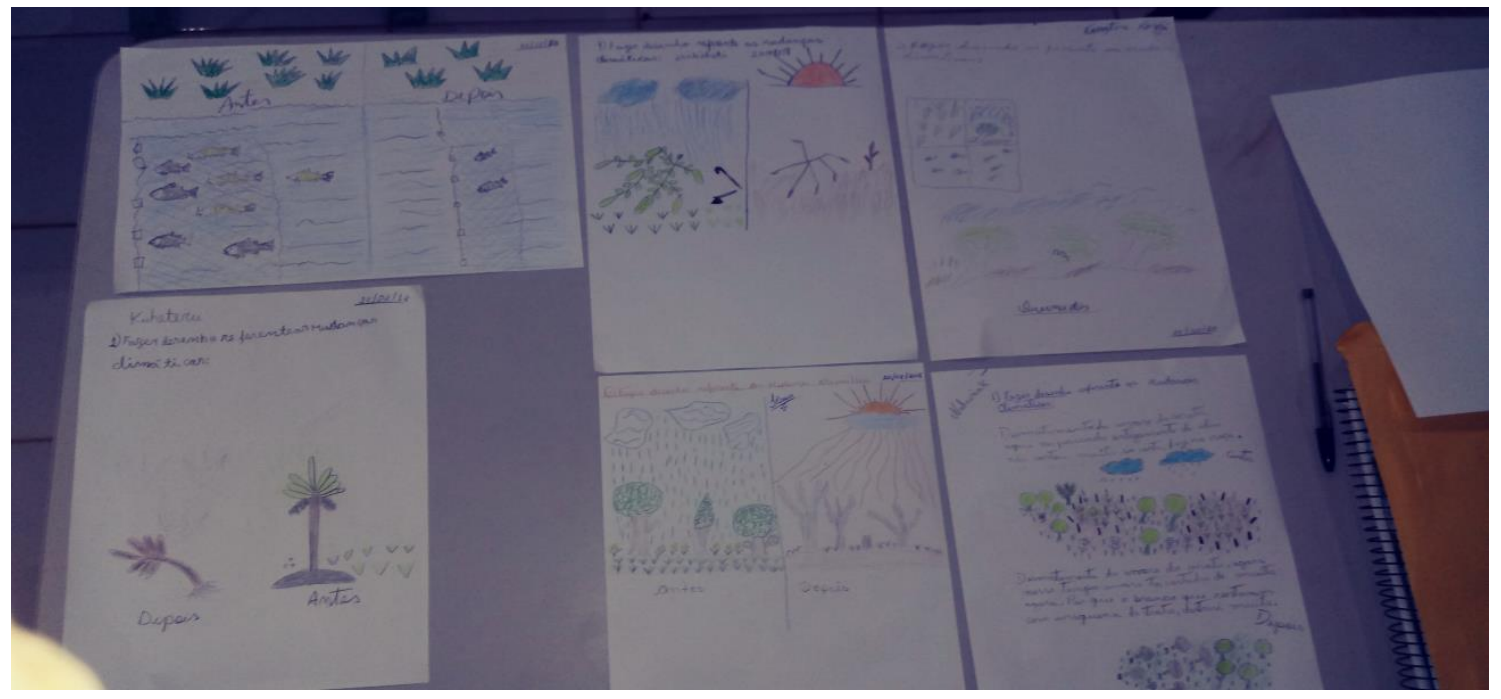

Fonte: Kanari Karajá (2018).

E a terceira pergunta foi ao contrário, "Como era antigamente, na observação de cada um de vocês, sem essas mudanças climáticas?" Então, cada um respondeu a questão do mesmo jeito, cada aluno ou aluna respondeu essa pergunta. De acordo com as respostas dos alunos e alunas e também da minha observação, "Antigamente a temperatura do sol era normal e não fazia muito calor como faz atualmente, no período de chuva chovia no tempo certo que começava no mês de setembro, o nível do rio Araguaia quando era período de cheia ficava no nível considerado normal, e quando chegava o período de seca, o Rio Araguaia baixava de maneira que era considerado normal, e no período de cheia, era uma fartura no rio Araguaia, muitos cardumes subindo. Esse era o momento mais esperado pelos Iny que usufruíam desses cardumes para alimentar suas famílias ou para vender e fazer compras de acordo com a necessidade de sua família, e antigamente as queimadas eram muito poucas, comparando com a atual realidade".

Nesse primeiro Estágio I, o meu objetivo era abrir a visão de cada aluno(a) sobre essas mudanças climáticas que vem ocorrendo nesses anos todos, alterando a natureza desse planeta onde vivemos, e nos deixando confusos com as mudanças que alteram nossas vidas e nossas atividades econômicas e de alegria.

Para aplicar o tema contextual, na sala de aula, precisei de materiais como caderno, caneta, lápis, borracha, folha branca, lápis de cor, giz, quadro negro, para que cada aluno(a), no 
final da aula, fizessem uma atividade de acordo com o tema contextual trabalhado, por exemplo, desenhos sobre as mudanças climáticas, leituras, observação da natureza envolvendo o tema proposto por mim.

No dia 16 de junho de 2018, terminei de dar aula de Estágio I, na sexta-feira, às 9h30 da manhã, com tema contextual "Mudanças Climáticas", na Escola Estadual Indígena Krumare que se localiza na Aldeia JK, na Ilha do Bananal, Município de Lagoa da Confusão-TO. No final da aula, eu agradeci cada aluno e aluna por fazer parte da minha primeira experiência do Estágio, porque foi um grande desafio para mim. Por fim, a aula foi bastante proveitosa e rica em conhecimentos interculturais. Agradeço a Professora Maria Do Socorro Pimentel da Silva por ser minha orientadora, nesse Estágio I, e muito obrigado.

\section{Txiòtòètukè.}

\section{Estágio II: Tema Contextual Mudanças Climáticas}

No dia 16 a 20 de outubro de 2018 comecei a dar aula de Estágio II com o mesmo tema contextual do Estágio I, dando uma continuidade ao trabalho que fiz no primeiro Estágio, mas agora para a turma de $1^{\circ}$ ano e $2^{\circ}$ ano de Ensino Médio, durante o período da manhã, das $8 \mathrm{~h}$ às 9h30, de segunda-feira a sexta-feira, na Escola Estadual Indígena Krumare que se localiza na Aldeia JK, na Ilha do Bananal, município de Lagoa da Confusão-TO.

Com essa turma, meu objetivo era adquirir mais conhecimento sobre esse tema. Minha proposta era que cada aluno e aluna fizessem uma pesquisa sobre mudanças climáticas, no site de pesquisa, para que todos e todas pudessem conhecer um pouco mais desse fenômeno que vem causando mudanças no planeta inteiro, incluindo as comunidades indígenas.

Quando comecei a dar aula, fizemos a problematização do tema para dar início à pesquisa científica, no site de pesquisa, sobre "O aquecimento global"?

Aquecimento global é o aumento da temperatura média dos oceanos e da camada de ar próxima à superfície da Terra que pode ser consequência de causas naturais e atividades humanas. Isto se deve principalmente ao aumento das emissões de gases na atmosfera que causam o efeito estufa, principalmente o dióxido de carbono $(\mathrm{CO} 2)$. 
O efeito estufa? O efeito estufa corresponde a uma camada de gases que cobre a superfície da Terra, essa camada composta principalmente por gás carbônico $\left(\mathrm{CO}^{2}\right)$, metano $(\mathrm{CH} 4), \mathrm{N}^{2} \mathrm{O}$ (óxido nitroso) e vapor d água, é um fenômeno natural fundamental para a manutenção da vida na Terra, pois sem ela o planeta poderia se tornar muito frio, inviabilizando a sobrevivência de diversas espécies. Normalmente, parte da radiação solar que chega ao nosso planeta é refletida e retorna diretamente para o espaço, outra parte é absorvida pelos oceanos e pela superfície terrestre, e uma parte é retida por esta camada de gases que causa o chamado efeito estufa. $\mathrm{O}$ problema não é o fenômeno natural, mas o agravamento dele. Como muitas atividades humanas emitem uma grande quantidade de gases formadores do efeito estufa (GEEs), esta camada tem ficado cada vez mais espessa, retendo mais calor na Terra, aumentando a temperatura da atmosfera terrestre e dos oceanos e ocasionando o aquecimento global.

São várias as consequências do aquecimento global e algumas delas já podem ser sentidas em diferentes partes do planeta. Os cientistas já observam que o aumento da temperatura média do planeta tem elevado o nível do mar devido ao derretimento das calotas polares, podendo ocasionar o desaparecimento de ilhas e cidades litorâneas densamente povoadas. E há previsão de uma frequência maior de eventos extremos climáticos (tempestades tropicais, inundações, ondas de calor, seca, nevascas, furacões, tornados e tsunamis).

As mudanças climáticas podem ter causas naturais como alterações na radiação solar e dos movimentos orbitais da Terra ou podem ser consequência das atividades humanas. O Painel Intergovernamental de Mudanças Climáticas (IPCC), órgão das Nações Unidas, responsável por produzir informações científicas, afirmam que há 90\% de certeza que o aumento de temperatura na Terra está sendo causado pela ação do homem. A partir da Revolução Industrial, o homem passou a emitir quantidades significativas de gases de efeito estufa (GEE), em especial o dióxido de carbono. Neste período, a concentração original de 280 ppm4 deste gás cresceu até os atuais 400 ppm5, intensificando significativamente o efeito estufa. Assim, as atividades humanas passaram a ter influência importante nas mudanças climáticas.

E, depois da problematização, fizemos a contextualização do tema abordado. Quando os alunos terminaram de fazer a pesquisa, eu fiz uma pergunta referente às mudanças climáticas para meus alunos e alunas. Na visão de cada um de vocês, quais mudanças vocês vem observando ao longo desses anos?

R. Articul.const.saber, 2021, v.6: e67313 
Figura 3 - O rio Araguaia no período de seca

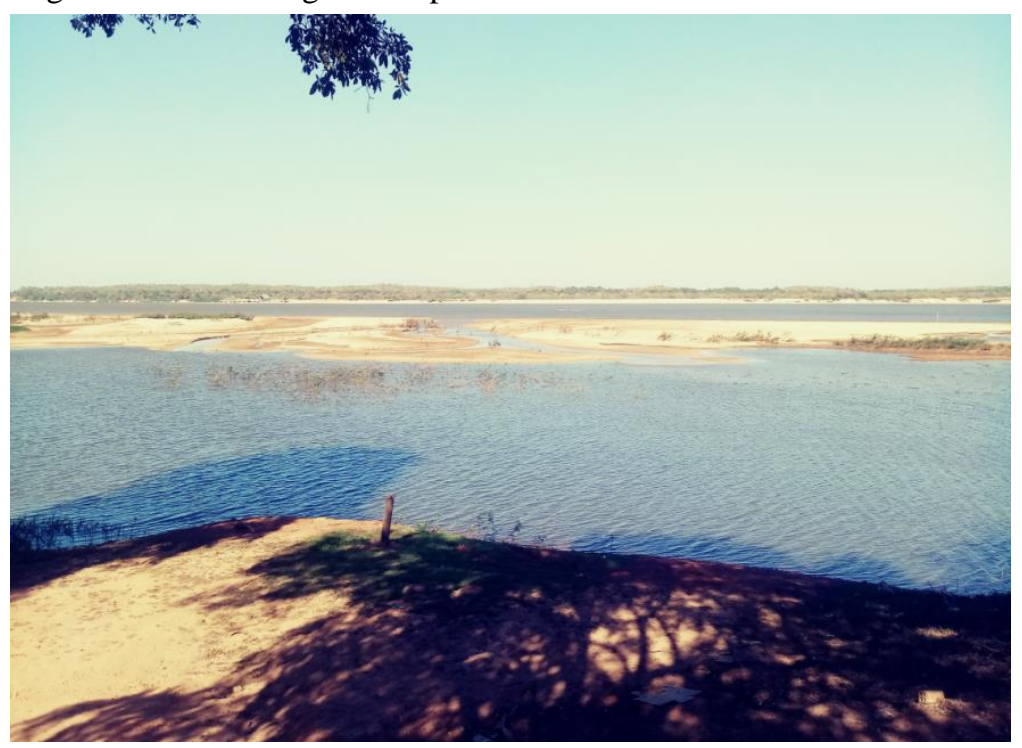

Fonte: Kanari Karajá (2017).

O rio Araguaia, no período de seca, a situação é bem crítica, fora do normal, isso é um dos efeitos das mudanças climáticas. Essa foto foi tirada no ano de 2017.

Figura 4 - Foto tirada do mesmo lugar, no período de seca, em 2018.

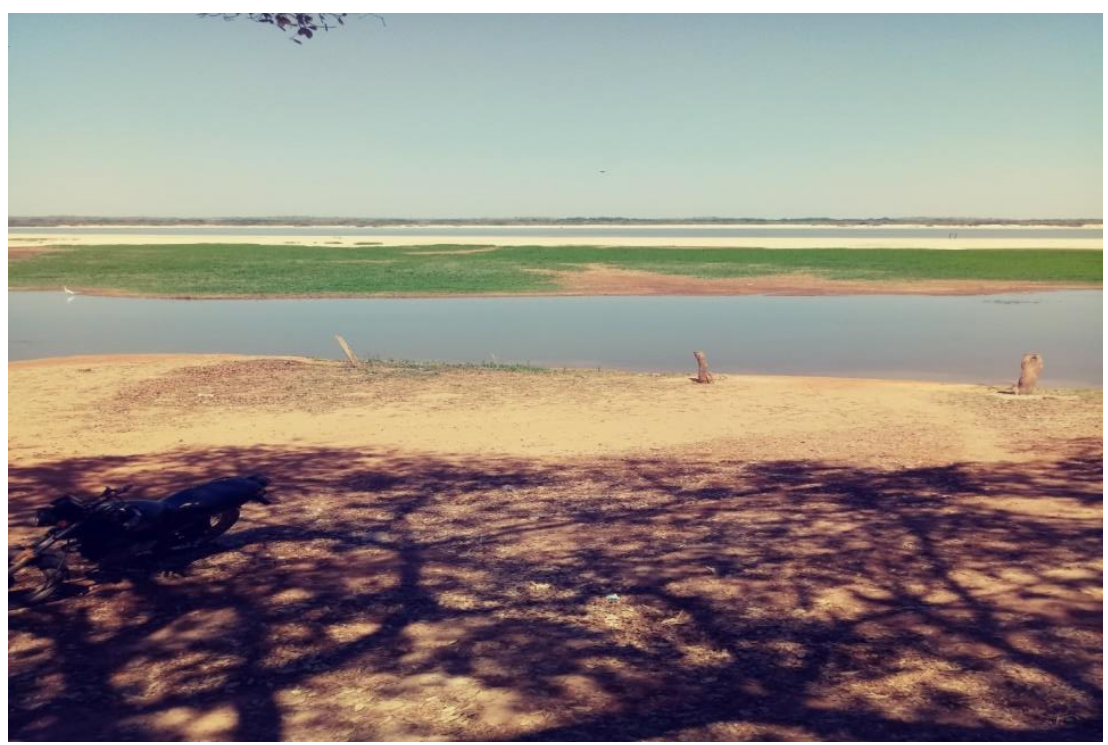

Fonte: Karani Karajá (2018). 
A foto acima foi tirada no mesmo lugar, no período de seca, no ano seguinte, em 2018. Isso mostra a situação do rio Araguaia com as mudanças climáticas no decorrer do tempo.

Todos e todas responderam que as mudanças que observaram foi o baixo nível do rio Araguaia no período de seca. Neste, a situação do rio é bem crítica e fora do normal. Isso é um dos principais efeitos dessas mudanças climáticas. Quando pensamos por que isso está acontecendo, é por causa da ação do homem, as principais atividades humanas que causam o aquecimento global e consequentemente as mudanças climáticas é a queima de combustíveis fósseis (derivados do petróleo, carvão mineral e gás natural) para geração de energia, atividades industriais e transportes; conversão do uso do solo; agropecuária; descarte de resíduos sólidos (lixo) e desmatamento. Todas estas atividades emitem grande quantidade de $\mathrm{CO}^{2}$ e de gases formadores do efeito estufa. A metodologia usada durante o trabalho, na sala de aula, com os alunos e alunas, foi pedir para que fizessem uma pesquisa na internet referente às mudanças climáticas e depois anotassem partes importantes para elaboração de texto de redação contando sobre as mudanças climáticas no planeta e na comunidade indígena em geral.

A atividade que passei para os(as) alunos(as) foi a uma elaboração de redação do tema proposto e cada aluno fez uma pesquisa na internet para obter mais informações sobre as mudanças climáticas. Durante as aulas também fiz avaliação dos(as) alunos(as), foram avaliados de acordo com a participação de cada um nas atividades proposta por mim na sala de aula.

No dia 20 de outubro de 2018 terminei de dar aula de Estágio II, dando continuidade do trabalho que fiz no primeiro Estágio para turma de EJA e, no entanto, dei a continuidade do mesmo tema para turma de $1^{\circ}$ ano e $2^{\circ}$ ano de Ensino Médio, durante o período da manhã, às 9h30, na sexta-feira, na Escola Estadual Indígena Krumare que se localiza na Aldeia JK, na Ilha do Bananal, município de Lagoa Da Confusão-TO. No final da aula, eu agradeci cada um dos(as) meus/minhas alunos(a) por fazer mais um vez parte da minha experiência de Estágio II com o tema contextual "Mudanças Climáticas".

\section{Estágio III - Tema Contextual Grafismo do Povo Iny}

Do dia 19 a 23 de março de 2019 comecei dar a aula de Estágio III para turma de $6^{\circ}$ ano e $7^{\circ}$ ano, durante o período da manhã, das $8 \mathrm{~h}$ às $9 \mathrm{~h} 30$, de segunda-feira a sexta-feira, com o tema 
contextual "Grafismo do Povo Iny", na Escola Estadual Indígena Krumare que se localiza na Aldeia JK, na Ilha do Bananal, município de Lagoa da Confusão-TO.

Antes de aplicar o estágio, eu fiz uma entrevista com uma anciã Korixo Karajá residente na Aldeia JK. Ela é a minha avó materna e uma grande artesã, conhecedora de vários conhecimentos, incluindo o Grafismo Iny. Durante a entrevista eu fui anotando no caderno o que ela estava relatando para mim e isso foi de suma importância para mim durante o trabalho com esse tema na sala de aula.

Como de costume, durante o primeiro dia de aula do tema contextual fiz uma pergunta sobre o que é tema contextual para os(as) meus/minhas alunos(a). Mas ninguém sabia do que se tratava, então, tive de explicar que o tema contextual é um conhecimento que abrange vários conhecimentos dentro de um só, tema incluindo conhecimento Iny que é intracultural e, ao mesmo tempo, pode ter conhecimento não Iny dentro desse contexto. Assim vai se esticando e articulando os saberes no contexto da educação intercultural.

O meu objetivo de trabalhar com esse tema foi incentivar os(as) alunos(as) a não deixarem de lado esse conhecimento que é muito importante não só para o povo Iny, mas, também, para outros povos indígenas, porque o Grafismo é uma identidade de cada povo, através do Grafismo podemos identificar pessoas de outros povos.

O Grafismo pode ser usado de várias formas no conhecimento do Iny mahãdu (povo Iny), como por exemplo, no artesanato, na esteira, na ritxoo (boneca de cerâmica), no banquinho dos Jyrè (meninos em iniciação cultural), no Remo, nos adornos de rapazes e moças, como Myrani (colar) e Wètaana (cinto) e, por último, a pintura corporal. O povo Iny tem o ciclo de vida bem organizado, desde o nascimento até a fase adulta, tanto masculino quanto feminino, isso já é um costume do Povo Iny que foi passado de geração em geração até atual realidade. 
Figura 5 - Ritxoo (Boneca de Cerâmica)

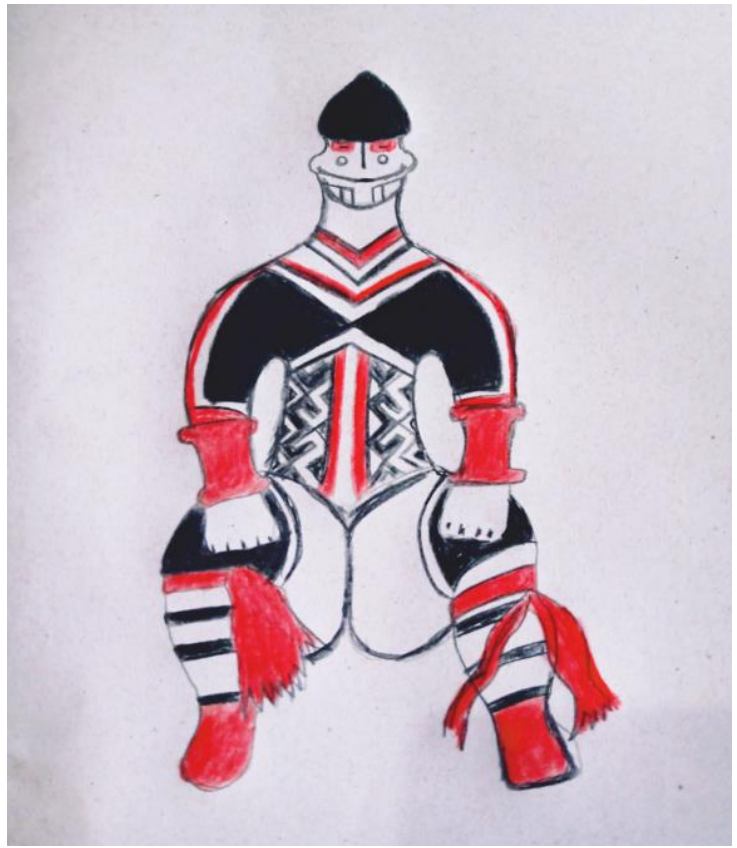

Fonte: Karani Karajá (2019).

Figura 7 - Rti (Grafismo Iny)

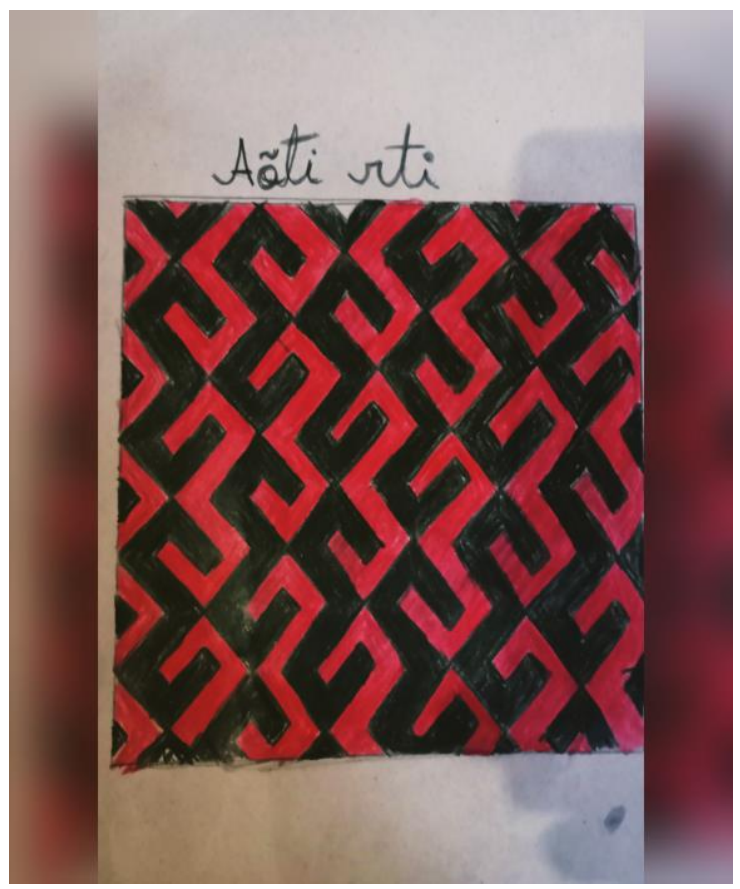

Fonte: Karani Karajá (2019).
Figura 6 - Myrani (Colar)

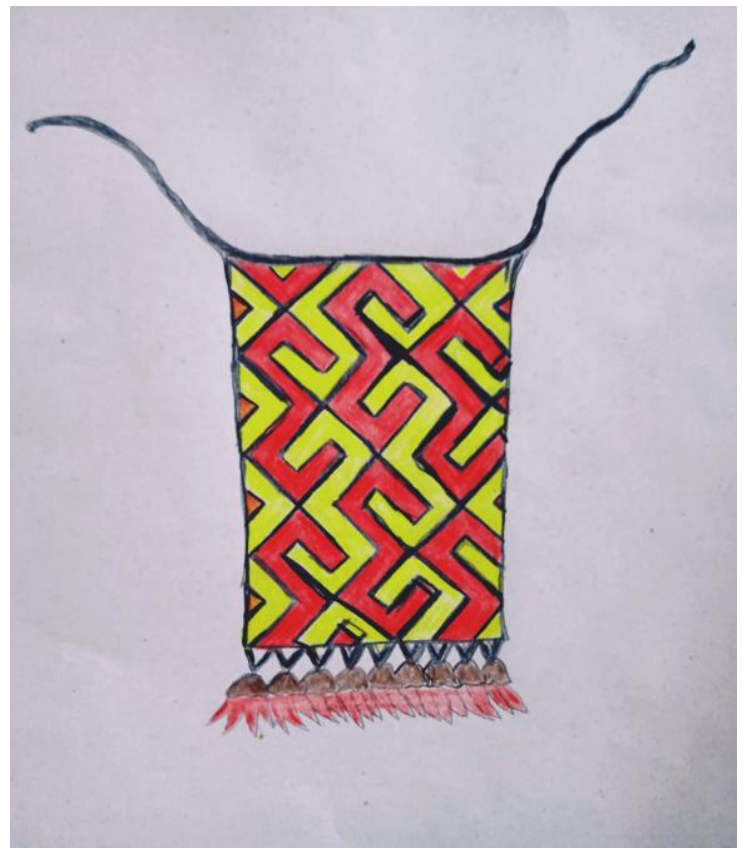

Fonte: Karani Karajá (2019).

Figura 8 - Wètaana (Cinto)

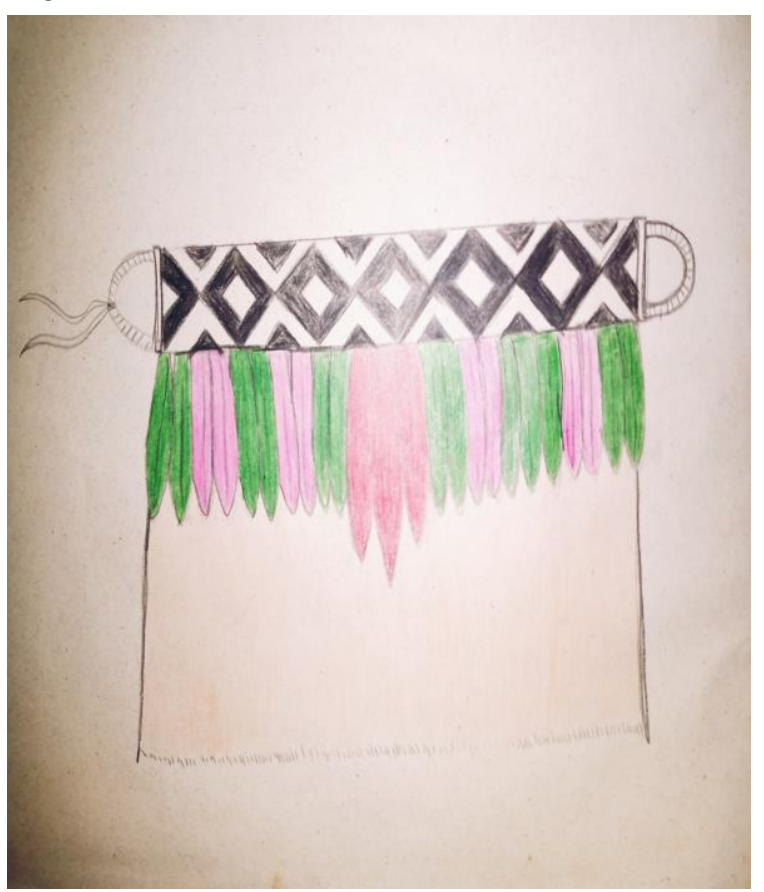

Fonte: Karani Karajá (2019). 
Figura 9 - Iny Yri (Pintura Corporal)

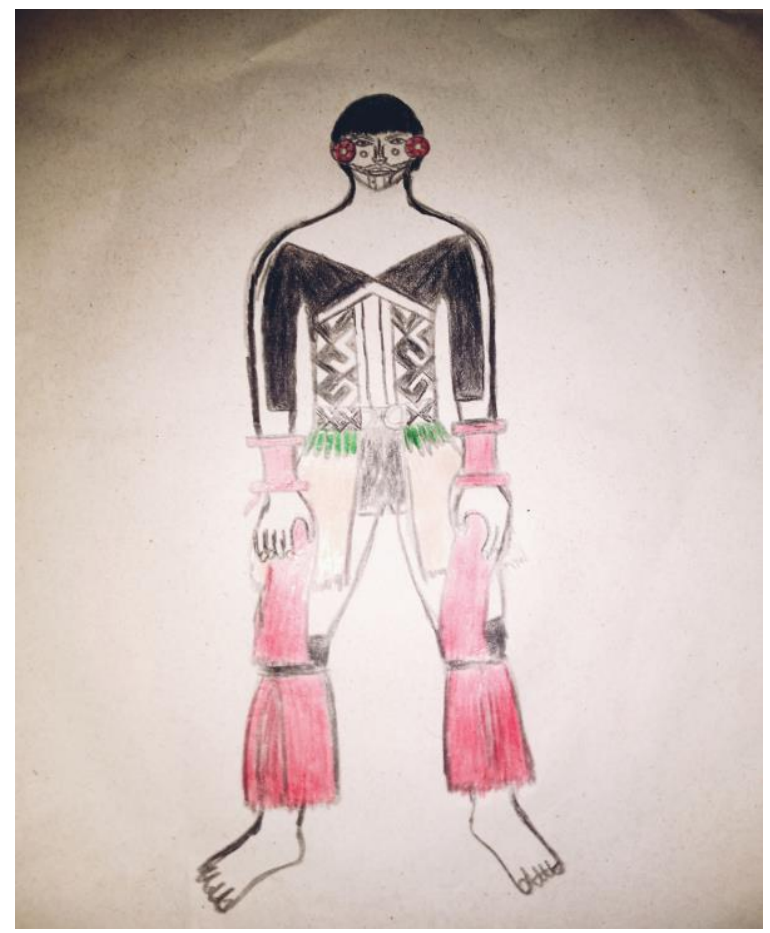

Fonte: Karani Karajá (2019).

Como os(as) alunos(as) eram turmas de $6^{\circ}$ ano a $7^{\circ}$ ano, eu fiz uma proposta para cada um dos(as) meus/minhas alunos(a) fazerem um desenho de Grafismo de acordo com o seu conhecimento sobre o Grafismo, valendo como atividade para o final do tema, para cada um explicar na frente da sua turma, na sala de aula, na última semana do seu trabalho com o tema contextual. As metodologias que usei durante a aula para aplicar o tema contextual foram: a busca do conhecimento por meio da pesquisa, problematização sobre a manutenção cultural e a contextualização dos conhecimentos na composição do tema contextual.

E, por fim, agradeço cada um dos(as) meus/minhas alunos(as). Além deles aprenderem comigo eu também aprendi muito com os meus alunos. Ser professor não é fácil, tem que ter amor ao trabalho e dedicação total aos alunos, porque é o futuro deles que está em jogo. E meus agradecimentos a minha professora e orientadora Maria do Socorro Pimentel da Silva e a minha querida avó Korixo Karajá que contribuíram muito nessa longa caminhada acadêmica. 


\section{Estágio IV: Tema Contextual Bebida Alcoólica}

Do dia 20 a 24 de maio de 2019 comecei a dar aula de Estágio IV para a turma de $6^{\circ}$ ano e $7^{\circ}$ ano, durante o período da manhã, das $8 \mathrm{~h}$ a $9 \mathrm{~h} 30$, de segunda-feira a sexta-feira, com o tema contextual "Bebiba alcoólica", na Escola Estadual Indígena Krumare que se localiza na Aldeia JK, na Ilha do Bananal, município de Lagoa da Confusão-TO. O tema que trabalhei nesse Estágio IV foi a bebida alcoólica. Por que eu escolhi trabalhar com esse tema? O meu conceito era dar aula sobre a bebida alcoólica e falar sobre as suas enfermidades para saúde, o que pode ocasionar através do consumo da bebida alcoólica, ao longo prazo. Para dar início à aula, eu fiz uma pergunta sobre o tema abordado para entrar no contexto do tema contextual. Perguntei para meus alunos e alunas o que eles e elas entendem sobre a bebida alcoólica?

Os/as alunos e alunas responderam que a bebida alcóolica não faz bem a saúde, gera muita coisa ruim como acidentes, brigas, mortes, afogamentos, suicídios, entres outros. Então, eu falei que cada resposta dos alunos estava correta. Durante as aulas também fiz uma palestra na sala de aula sobre as bebidas alcoólicas e suas enfermidades para saúde.

Um dos meus propósitos era a conscientização dos(as) alunos(a) que, em nenhum momento, eles e elas poderiam se envolver com as bebidas alcoólicas que só fazem mal a saúde.

Eu também envolvi a comunidade para debater na Escola Estadual sobre a bebida alcoólica e os grandes problemas que ela traz, nas aldeias em geral, e como podemos diminuir isso.

Para entender um pouco mais sobre o tema, eu dei um texto para os meus alunos e alunas sobre o tema proposto para fazerem uma leitura e compreensão do texto. "O consumo de bebida alcoólica pode causar diversas outras enfermidades como a esteatose, que é o acúmulo de gordura no fígado, a qual pode evoluir para uma cirrose. Esta, por sua vez, frequentemente não tem reversão e só é curada através de um transplante de fígado. O doente fica com a pele amarelada, desnutrido, com a barriga inchada e sente fortes dores abdominais. Pode causar também sangramento pelo nariz e vômitos. Outra doença comum é uma inflamação no miocárdio, chamada miocardite, que se caracteriza por tonturas e falta de ar, que por sua vez são causadas por uma arritmia cardíaca". Retirei esse texto do site Infoescola (www.infoescola.com/doencas/doencas/alcoolismo). 
Pode causar, ainda, uma inflamação no pâncreas, denominada pancreatite, que se manifesta através de dores de barriga e diarreia, e caso não seja tratada pode se transformar em diabetes. A Neuropatia, que é uma alteração nos nervos, é caracterizada pela perda do tato e formigamentos nas mãos. E, por fim, pode causar uma lesão no cérebro que compromete a memória e altera drasticamente o comportamento do indivíduo. Conforme as informações que consegui no site Infoescola (www.infoescola.com/doencas/doencas/alcoolismo).

A metodologia que eu adotei foi fazer uma palestra dentro da aula com o objetivo de conscientizar alunos e alunas para que futuramente tenham consciência que não possam se envolver em nenhum momento com bebidas alcoólicas que são tão maléficas a saúde. Durante a aula, eu e meus alunos e alunas fizemos uma pesquisa na internet, nos livros, para obtermos informações suficientes para fazer as atividades propostas por mim. Recursos necessários para produção de textos com o tema contextual bebida alcoólica: ter acesso à internet, caderno, caneta, lápis, borracha, folha branca, cartolinas.

No final da aula do tema contextual fiz atividade final para os alunos que era para fazer uma redação com o tema contextual "Bebida alcoólica". A redação deve conter introdução, desenvolvimento e conclusão sobre o tema contextual abordado por mim. Essa redação deve conter no mínimo 20 linhas. Por fim, os alunos também foram avaliados de acordo com a participação na sala de aula, no debate na aula, na produção de textos, como por exemplo, a redação.

Na sexta-feira, dia 24 de maio de 2019, às 9h30 da manhã, terminei a aula com o tema contextual "Bebida Alcoólica", na Escola Estadual Indígena Krumare, com a turma de $6^{\circ}$ ano e $7^{\circ}$ ano. Para mim foi um grande aprendizado na minha formação como docente e agradeço a todos os envolvidos, inclusive os meus caros alunos e alunas e toda a comunidade da minha aldeia e muito obrigado.

\section{Estágio V: Tema Contextual Lixo na Aldeia}

Do dia 21 a 25 de outubro de 2019 comecei a dar aula de Estágio V para as turmas de $8^{\circ}$ ano e $9^{\circ}$ ano, durante o período da manhã, das 8 h a 9 h30, de segunda-feira a sexta-feira, com o 
tema contextual "Lixo na Aldeia", na Escola Estadual Indígena Krumare que se localiza na Aldeia JK, na Ilha do Bananal, município de Lagoa da Confusão-TO.

No meu Estágio $\mathrm{V}$ trabalhei com a turma de $8^{\circ}$ ano e $9^{\circ}$ ano com o objetivo de conscientizar os(as) alunos(as) da minha comunidade que lugar de lixo é na lixeira. Não podemos jogar lixos nos arredores de casas, nas matas, nos rios e na beira das estradas. Além de ensinar meus alunos e alunas a fazer uma coleta de lixo nas aldeias, para a redução de lixo, tinha como objetivo mostrar para a comunidade que podemos ser um bom exemplo para outras aldeias.

Junto com meus alunos e alunas fizemos uma problematização do tema: Lixo tem sido uma das minhas preocupações, na minha aldeia, porque cada vez mais vem acumulando lixos nos arredores das casas, nas matas, na beira das estradas, até no rio Araguaia vejo lixos boiando. Isso é bastante preocupante e, na minha concepção, é obrigação de cada pessoa ter noção que lixo não faz bem a saúde, que lixo atrai baratas, ratos, moscas, com elas trazendo em si doenças que podem ser transmitidas através desses seres maléficos.

Esses lixos que se encontram nas aldeias são trazidos direto da cidade através das compras que os Iny fazem durante a feira que é feita dentro de cada mês. Com isso, cada vez mais vai acumulando a cada ano que se passa o lixo dentro da aldeia. Como professor, é minha obrigação dialogar com meus alunos e alunas sobre essa questão do lixo e, também, dialogar com o pessoal da minha comunidade. Fizemos, ainda, uma contextualização do tema para facilitar e passei uma leitura do texto para os alunos e alunas compreenderem mais sobre o tema abordado por mim.

A questão do lixo está diretamente ligada ao modelo de desenvolvimento que vivemos, vinculada ao incentivo do consumo, pois muitas vezes adquirimos coisas que não são necessárias, e tudo que consumimos produz impactos no meio ambiente. Há aproximadamente 40 anos a quantidade de lixo gerada era muito inferior à atual, hoje a população aumentou, a globalização se encontra em um estágio avançado, além disso, as inovações tecnológicas no seguimento dos meios de comunicação (rádio, televisão, internet, celular etc.) facilitaram a dispersão de mercadorias em nível mundial.

Antes do processo da Primeira Revolução Industrial, o lixo produzido nas residências era composto basicamente de matéria orgânica. Dessa forma, era fácil eliminá-los, bastava enterrar. Além disso, as cidades eram menores e o número da população restrita. 
Mais tarde, o crescimento em escala mundial da industrialização e o acelerado aumento da população e dos centros urbanos, que ocorreu principalmente na segunda metade do século $\mathrm{XX}$, desencadeou um aumento significativo na quantidade de lixo e variedades em suas composições. Atualmente, quando compramos algo no supermercado, o lixo não é apenas gerado pelo produto em si, pois existe a etapa de produção (cultivo, extração de minérios, transporte, energia) e depois, para o consumidor final, tem a sacola e o cupom fiscal.

Nas cidades que contam com serviços de coleta do lixo, este é armazenado em dois tipos de "depósitos": os lixões nos quais os dejetos ficam expostos a céu aberto e os aterros sanitários onde o lixo é enterrado e compactado.

A metodologia adotada por mim para trabalhar com essa turma foi uma ação de coleta de lixo dentro da comunidade e arredores da Escola, palestra sobre o lixo na Escola Estadual Indígena Krumare, materiais para uso na coleta de lixo como: luvas, sacos plásticos de 100 litros.

Figura 10 - Lixos nas matas poluindo o solo

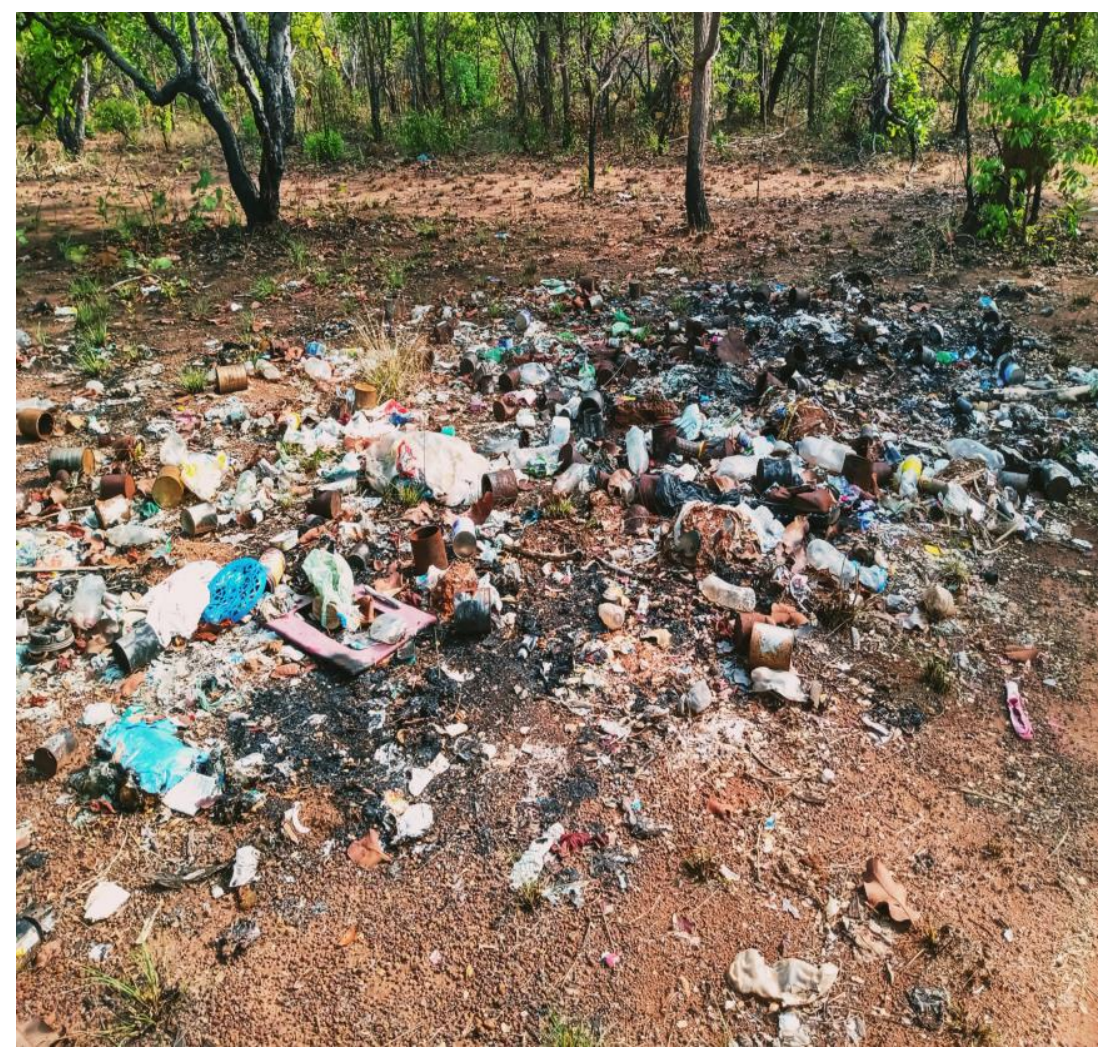

Fonte: Karani Karajá (2019). 
Figura 11 - Lixos

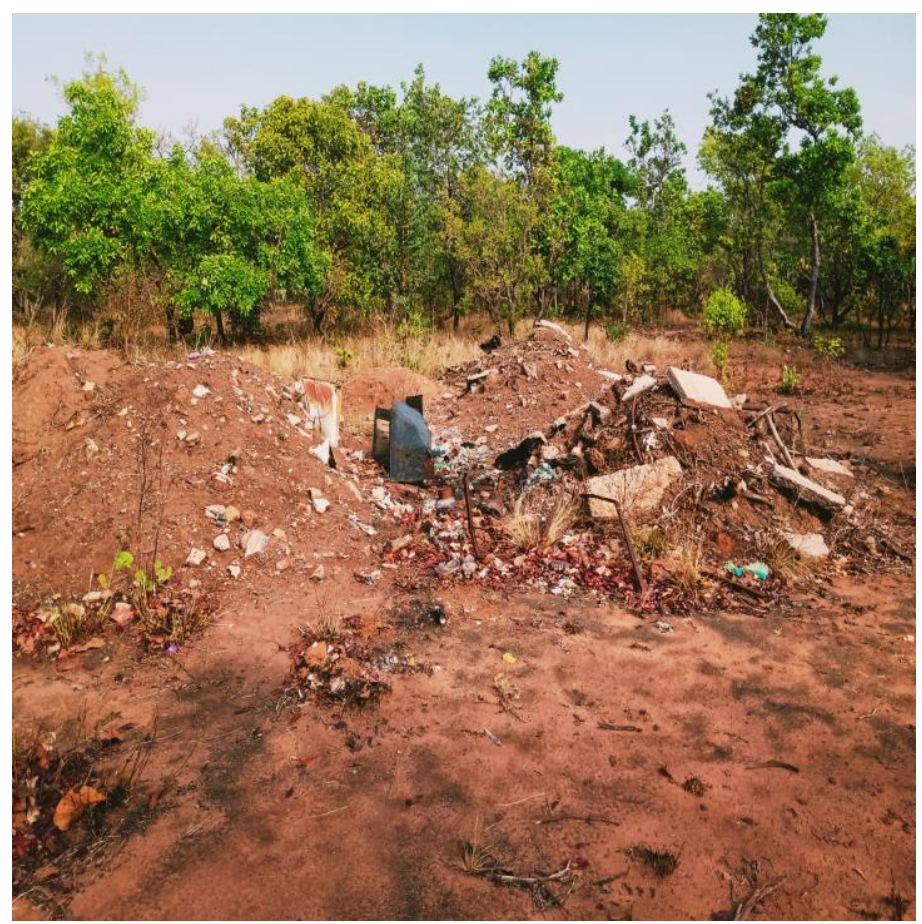

Fonte: Karani Karajá (2019).

O propósito desse tema abordado, na sala de aula, tem como objetivo conscientizar cada aluno e aluna, na Escola, e tanto a comunidade em geral, para que cada pessoa faça a sua parte em não jogar lixo nos arredores das casas, nas matas ou no rio, porque isso prejudica tanto a natureza como o ser humano.

Durante a aula, fizemos atividades envolvendo a turma e a comunidade onde eu moro, alunos(as) participaram da ação de coleta de lixo nos arredores da Escola Estadual Indígena Krumare e na comunidade da Aldeia JK valendo atividade principal do tema proposto por mim no final da aula do tema.

E também fiz avaliação de cada aluno(a), de acordo com a participação de cada um nas atividades propostas, por mim, na sala de aula e fora dela.

No dia 25 de outubro de 2019, terminei de dar aula de Estágio V para as turmas de $8^{\circ}$ ano e $9^{\circ}$ ano, às 9h30 da manhã, na sexta-feira, com o tema contextual "Lixo na Aldeia", na Escola Estadual Indígena Krumare que se localiza na Aldeia JK, na Ilha do Bananal, município de Lagoa da Confusão-TO. 
Como esse Estágio V era o último trabalho da minha formação docente eu agradeci cada um dos meus alunos e alunas por fazerem parte da minha experiência, porque foi um momento maravilhoso de se trabalhar. Sinto que eu abri a visão de cada um dos alunos e alunas sobre o lixo e toda a comunidade em geral.

\section{Considerações sobre minhas metodologias}

Em todas as etapas de estágio, busquei articular os dois conhecimentos. Conhecimento não indígena e conhecimento Iny. Isto é importante para os/as alunos/as entenderem sobre a importância dos dois conhecimentos. Assim, em todos os temas fiz esticamentos dos conhecimentos. Meus objetivos eram que os/as alunos/as da minha comunidade compreendessem um pouco mais do mundo não indígena e também a epistemologia do Povo Iny fez-se importante na composição dos temas contextuais. Isso é minha postura pedagógica na educação intercultural.

A participação das anciãs nesses estudos foi de suma importância para o desenvolvimento do meu trabalho de estágio onde comecei adquirir mais conhecimento e compreender a importância do conhecimento da oralidade que tem um valor imensurável na minha comunidade Iny mahãdu. Tenho o maior orgulho disso.

No meu conceito, o tema contextual contribuiu muito na escola onde trabalhei com os estágios, os alunos acharam muito interessante a aula com tema contextual, porque não só envolve os alunos, como também a comunidade e, assim, os alunos ficam mais interessados em aprender e conhecer o mundo da interculturalidade.

A metodologia adotada contribuiu de maneira bem significativa na elaboração e organização do meu trabalho de estágio:

- Pesquisa no campo para poder conhecer, aprender e ensinar os alunos

- Entrevista em outras aldeias vizinhas

- Documentação em fotos, escrita, e na oralidade.

- Realização de oficinas, palestras, coletas de lixo, e apresentação de atividades. 


\section{Resultados}

Esse estágio trouxe um ótimo resultado na escola onde trabalhei com tema contextual. Creio que os alunos da minha comunidade tiveram um novo olhar e um bom incentivo em aprender mais e mais em relação ao mundo da interculturalidade e intraculturalidade.

O meu objetivo, nesse meu trabalho de estágio, era fazer os meus alunos e alunas terem um pouco da noção de como funciona o mundo indígena e o mundo não indígena, ambos estão interligados, atualmente. Mas antigamente não eram.

Durante esses três anos de estágio não só aprendi a dar aula, bem como também aprendi a entender o papel importante de ser professor. É uma responsabilidade muito grande e, por outro lado, é muito gratificante ver os alunos aprenderem o que o professor repassa de seu conhecimento para os alunos e alunas. É uma sensação sem igual.

Ser professor de tema contextual é ensinar o mundo da interculturalidade, intraculturalidade e transdisciplinaridade, enriquecendo a metodologia de ensino de forma mais eficiente.

\section{Inovação pedagógica}

O tema contextual vem transformando a metodologia de trabalho, na sala de aula, fazendo com que a aula fique rica em conhecimentos interculturais através de temas abordados pelo professor que trabalha com tema contextual. Trabalhar com tema contextual é muito gratificante. Quando comecei a trabalhar com tema contextual abriu uma nova visão de dar aula, quem já trabalhou com tema contextual sabe o quanto é maravilhoso de se trabalhar.

Como qualquer ser humano, tive dificuldade de entender como se dava o estágio na sala, mas com a ajuda do meu comitê, da minha orientadora e de meus colegas, eu fui aprendendo cada vez mais durante a orientação que acontecia todas as manhãs de sábados durante a etapa presencial do curso, no Núcleo Takinahakỹ, e durante a etapa em terra indígena que acontece nas aldeias. Com o passar do tempo eu fui aprendendo, passo a passo, como fazer pesquisa, entrevista, plano de aula e, depois, foi facilitando cada vez mais, quando eu fazia do estágio I ao 
estágio V, sendo que o estágio VI era elaborar um relatório de cada estágio trabalhado. A cada estágio foi um grande aprendizado e aprofundava ainda mais a minha experiência como professor de tema contextual.

Nos diferentes temas contextuais lecionados no NTFSI, compreendo que a ideia de interculturalidade complementa à transdisciplinaridade e vice versa, tanto que sua maior expressão está na criação dos temas contextuais e na ideia de integrar o conhecimento, sem separá-lo ou dividi-lo. Nas entrevistas e conversas informais com os professores indígenas, é impressionante como a todo o momento se referem aos temas contextuais, acreditam que esta forma de aprender e ensinar é a maneira adequada para eles. Para Pimentel da Silva (2014), é do reconhecimento de diferentes contextos de produção de conhecimento que nasce a ideia da Pedagogia da Contextualização que, segundo o seu próprio esquema, é o resultado da soma de: projeto extraescolar + estágio + temas contextuais = epistemologia intercultural.

\section{Considerações finais}

O estágio que eu fiz foi trabalhado de acordo com a realidade vivida pelo meu povo Iny e, para isso, selecionei alguns temas contextuais para ser trabalhado na sala de aula, como exemplo: Mudanças Climáticas, Grafismo do Povo Iny, bebida alcoólica, Lixo na Aldeia. A ideia é para a aula ser mais interessante e envolver os alunos e alunas da minha comunidade para que possam estudar esses temas que estão relacionados com a realidade vivida atualmente. E, atualmente, trabalho na Escola Estadual Indígena Krumare, onde estou completando três anos de trabalho, nessa escola, como professor.

Sei que essa pesquisa e trabalho de estágio vai ser de grande valia para os meus alunos e alunas, para a comunidade e para a escola. O impacto que essa indagação trouxe para minha comunidade é de valor imensurável porque contém o conhecimento das anciãs que repassam os conhecimentos oralmente, e principalmente o conviver do meu povo Iny com a natureza. Isso resulta em um bem viver da comunidade Iny mahãdu, e tanto a convivência de outras pessoas em geral, ou coletivo onde a natureza ensina e educa os Iny.

Durante a conclusão do meu trabalho de estágio pedagógico contei com o apoio da minha família, com o apoio da minha comunidade e da escola. Para mim foi um grande prazer trabalhar 
na sala de aula como professor de tema contextual e poder ver a alegria dos meus alunos e alunas ao trabalharem e estudarem comigo, com temas contextuais.

Sinto-me honrado em fazer parte da vida de cada um desses alunos e alunas que estudaram comigo e por poder mostrar o mundo da interculturalidade e da contextualização.

Creio que esse trabalho será um grande apoio aos professores e professoras indígenas que talvez futuramente precisem desses modos pedagógicos de construir conhecimentos com os estudantes, e também servirá de apoio metodológico para fazerem suas pesquisas.

\section{Referências}

\section{Estágio I}

Anciã: KARAJÁ MAHÃLARU. Entrevistada sobre mudanças climáticas na Aldeia antigamente e atualmente sobre as mudanças ocorridas ao longo dos anos.

WWF Brasil. As mudanças climáticas. Disponível em:

https://www.wwf.org.br/natureza_brasileira/reducao_de_impactos2/clima/mudancas_climaticas2/

\section{Estágio II}

WWF Brasil. As mudanças climáticas. Disponível em:

https://www.wwf.org.br/natureza_brasileira/reducao_de_impactos2/clima/mudancas_climaticas2/

\section{Estágio III}

Anciã: KARAJÁ KORIXO. Conhecimentos que ela ensinou foi fazer Grafismo. Como o foco era o Grafismo, então, falei para ela mostrar como se faz Grafismos, um dos pontos mais importantes do tema.

\section{Estágio IV}

ARAÚJO, Ana Paula de. Bebidas alcoólicas. In: Infoescola Navegando e Aprendendo. Disponível em: < https://www.infoescola.com/drogas/bebidas-alcoolicas/>. Acessado em: 25 out. 2020.

MELDAU, Débora Carvalho. Alcoolismo. In: Infoescola Navegando e Aprendendo. Disponível em: 〈www.infoescola.com/doencas/doenças/alcoolismo〉. Acessado em: 25 out. 2020.

\section{Estágio V}

PEREIRA, Dayane Renata Silva. Temos que ajuntar o conhecimento: professores indígenas $e$ interculturalidade. 2015. Dissertação (Pós-Graduação em Antropologia Social) - Faculdade de Ciências Sociais, Universidade Federal de Goiás, Goiânia, 2015. 
PIMENTEL DA SILVA, Maria do Socorro. A pedagogia da esperança na construção de práticas pedagógicas contextualizadas e emancipatórias. In: PIMENTEL DA SILVA, Maria do Socorro; BORGES, Mônica Veloso (org.). Educação intercultural: experiências e desafios políticos pedagógicos. Goiânia: PROLIND/SECAD-MEC/FUNAPE, 2013. p. 68.

RETEC. Problemas que o lixo causa. In: Retec tecnologia em resíduos. Disponível em: http://www.retecresiduos.com.br/problemas-que-o-lixo-causa/. Acessado em: 25 out. 2020.

Submetido em 08 de janeiro de 2021.

Aceito em 23 de fevereiro de 2021.

Publicado em 12 de março de 2021. 